\title{
COLABORACIÓN INTERNACIONAL CON LA EASE: EXCELENCIA Y RESPONSABILIDAD
}

\author{
INTERNATIONAL COLLABORATION WITH THE EASE: \\ EXCELLENCE AND RESPONSIBILITY \\ Manuel Huamán-Guerrero 1,a,b,c, Jhony A. De La Cruz-Vargas 2,d,e,f
}

\begin{abstract}
T he European Association of Science Editors (EASE) es una organización internacional que incluye una comunidad de personas y asociaciones de diversos orígenes, tradiciones lingüísticas y experiencias profesionales en comunicación científica y edición. Actualmente tiene cerca de 400 miembros en más de 50 países alrededor del mundo y ha establecido un programa de Capítulos Regionales para facilitar la interacción entre editores dentro de países o grupo de países.
\end{abstract}

En el año 2016 tuvimos el honor como Universidad Ricardo Palma, a través del Instituto de Investigación en Ciencias Biomédicas-Facultad de Medicina Humana, de recibir la distinción de constituir el Peruvian Regional Chapter (Capitulo Regional Peruano) de la EASE, siendo el sexto capítulo internacional, el Primero en Sudamérica y el Segundo en Latinoamérica, después de México.

Los objetivos principales del Capitulo Regional Peruano de la EASE son:

- Organizar iniciativas de capacitación y otros eventos en Perú

- Desarrollar colaboraciones de editores en Perú y Latinoamérica

- Promover y apoyar las publicaciones de revistas peruanas

- Participar en diversas actividades promovidas por la EASE

La asociación ofrece la oportunidad de mantenerse al día en las tendencias en el entorno rápidamente cambiante de las publicaciones científicas y mantener los más altos estándares de calidad en dichas publicaciones.

Otros beneficios incluyen la suscripción automática a la revista trimestral, European Science Editing, con artículos relacionados con la ciencia y edición, reseñas de libros y web, noticias regionales y nacionales. Además, recursos y acceso gratuito a la Versión en Línea del Manual de Editores de Ciencias, que cubre todo, desde la edición en pantalla hasta la administración de la oficina, la revisión por pares y el trato con los medios de comunicación.

Las relaciones de colaboracion internacional son uno de los principios que puede enriquecer la estrategia de desarrollo de las organizaciones e instituciones. La colaboracion internacional acerca de los estandares de calidad en publicaciones cientificas, aporta elementos de experiencia, intercambio e innovacion, permite el acceso a nuevas ideas y enriquece las formas de trabajo.

Como Capítulo Peruano también formamos parte del comité de Políticas de Género de la EASE y estamos contribuyendo a difundir las Guías SAGER entre los países de habla hispana. El artículo que explica los fundamentos y recomendaciones para el uso de las directrices SAGER están publicadas en "Research Integrity", una revista con revisión por pares (http://researchintegrityjournal.biomedcentral.com/articles/10.1186/s41073-016-0007-6) y en el sitio web Equator: http://www.equator-network.org/reporting-guidelines/sager-guidelines/.

EASE: http://www.ease.org.uk

Peruvian Regional Chapter: http://www.ease.org.uk/about-us/regional-chapters/peruvian-regional-chapter/

Journal European Science Editing: http://europeanscienceediting.eu

Gender Policy Committee: http://www.ease.org.uk/about-us/gender-policy-committee/

Por todo ello nos complacemos en invitar a editores, investigadores, revisores, organizaciones académicas, y a toda la comunidad académica vinculada a investigación y publicación científica a participar activamente a través del Capitulo Regional Peruano, que abre sus puertas para recibir aportes, publicaciones, propuestas y a participar de las actividades programadas para el año 2017.

\footnotetext{
'Vicerrector Académico de la Universidad Ricardo Palma.

a Director General del INICIB.

b Editor en Jefe de la Revista de la Facultad de Medicina Humana.

c Doctor en Medicina y Especialista en Cirugía Oncológica.

${ }^{2}$ Director Adjunto del INICIB.

Coeditor de la Revista de la Facultad de Medicina Humana.

e Doctor en Medicina, Maestría en Investigación Clínica.

Especialista en Oncología Médica.
}

Citar como: Manuel Huamán-Guerrero, Jhony A. De La Cruz-Vargas. Colaboración internacional con la EASE: Excelencia y responsabilidad [Editorial]. Rev. Fac. Med. Hum. 2016;16(2):7. DOI 10.25176/RFMH.v16.n2.661 